\title{
Supplemental Table 1
}

Lifespan of $\mathrm{N}_{2}$ worms that were treated with skn-1 RNAi from different stages of life.

(Corresponding to Fig. 1A and B)

Strain: N2

\begin{tabular}{|l|l|l|l|l|l|}
\hline Treatment: & $n$ & Censored: & $\begin{array}{l}\text { Mean lifespan } \\
\text { (days) }\end{array}$ & $\begin{array}{l}\text { Standard error } \\
\text { (days) }\end{array}$ & $\begin{array}{l}\text { P value } \\
\text { compared to } \\
\text { control (EV) }\end{array}$ \\
\hline EV & 76 & 44 & 18.12 & 0.51 & $4.09 \mathrm{E}-04$ \\
\hline$s k n-1$ RNAi & 106 & 14 & 16.17 & 0.32 & $3.00 \mathrm{E}-05$ \\
\hline EV $\rightarrow$ skn- 1 RNAi (L2) & 99 & 21 & 15.98 & 0.24 & $2.60 \mathrm{E}-05$ \\
\hline EV $\rightarrow$ skn- 1 RNAi (L4) & 74 & 46 & 15.54 & 0.35 & 0.31 \\
\hline EV $\rightarrow$ skn- 1 RNAi (Day 1) & 108 & 12 & 17.83 & 0.31 & 0.18 \\
\hline EV $\rightarrow$ skn-1 RNAi (Day 5) & 70 & 50 & 17.51 & 0.42 & 0.27 \\
\hline EV $\rightarrow$ skn- 1 RNAi (Day 9) & 82 & 38 & 18.57 & 0.54 & \\
\hline
\end{tabular}

